\title{
Integrity in Authorship and Publication
}

\author{
James E Tisdale
}

$\mathrm{I}_{\mathrm{r}}^{\mathrm{n}}$

$\mathrm{n}$ recent years, seemingly frequent examples of problems related to the integrity of authorship and publication have plagued the medical literature. These issues have been primarily related to the appropriateness of authorship (including ghostwriting and so-called "guest authorship" of manuscripts), duplicate publication of articles, plagiarism, scientific misconduct in the form of falsification of data, and failure to disclose conflicts of interest. Although authorship and publication issues arise relatively rarely at the CJHP, the Journal has, on occasion, been faced with some of these concerns.

Two issues that have received attention recently in the scientific literature and even in the lay press are the ghostwriting and guest authorship of scientific articles. Ghostwriting has been defined as "the failure to designate an individual (as an author) who has made a substantial contribution to the research or writing of a manuscript." Particular attention was drawn to this practice in a review of industry documents obtained during litigation related to rofecoxib, ${ }^{1}$ in which it was discovered that numerous review articles had been prepared by people who were not recognized as authors or otherwise acknowledged. Instead, the authorship of these papers was attributed to investigators with academic affiliations. This review also revealed that many clinical trial manuscripts were written primarily by industry employees, with first authorship on each paper being attributed to an investigator with an academic affiliation. ${ }^{1}$ Research has identified ghostwriting in 13\% of research articles, $10 \%$ of review articles, $6 \%$ of editorials, and $11 \%$ of Cochrane reviews. ${ }^{1-3}$ Guest authorship has been defined as "the designation of an individual who does not meet authorship criteria as an author." ${ }^{1}$ Guest authorship includes the practice of naming as authors individuals in senior positions (e.g., the director of a laboratory) in recognition of their perceived "support" of the project, even if they did not contribute to conducting the study or writing the paper (sometimes referred to as "honorary authorship"). Guest authorship has been found in $16 \%$ of research articles, $26 \%$ of review articles, $21 \%$ of editorials, and $41 \%$ of Cochrane reviews. ${ }^{1-3}$ Ghostwriting and guest authorship are dishonest practices that undermine the medical and scientific literature. All authors of papers submitted to the CJHP must meet the authorship criteria of the International Committee of Medical Journal Editors (see http://www.icmje.org), which states that authorship credit should be based on "1) substantial contributions to conception and design, acquisition of data, or analysis and interpretation of data; 2) drafting the article or revising it critically for important intellectual content; and 3) final approval of the version to be published." Authors must

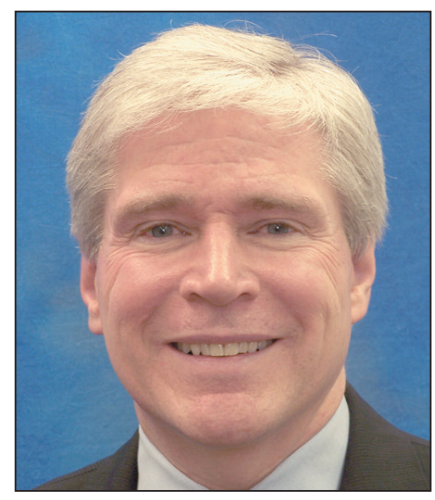
meet all of these criteria, and all individuals who meet these criteria must be listed as authors. Individuals who contributed to the study but who do not meet all of these criteria may be listed in the acknowledgements section of the manuscript, provided that they have given their permission to be acknowledged in this way.

Duplicate publication is "the simultaneous or subsequent reporting of essentially the same information, article, or major components of an article 2 or more times in 1 or more forms of media (either print or electronic format)." ${ }^{34}$ For authors with academic appointments, promotion and, in many cases, continued employment depend on the number of publications; the desire to publish as many papers as possible may thus be an incentive to engage in duplicate publication. In addition, authors have attempted to justify duplicate publication on the basis of a desire to disseminate information to as wide an audience as possible. ${ }^{5}$ However, duplicate publication of the same information in multiple articles is misleading, because it gives the impression of reproducibility of data, which lends greater weight to research findings. ${ }^{6}$ In addition, duplicate publications have been inadvertently included in meta-analyses and systematic reviews, which may contribute to inaccurate results. ${ }^{6.7}$ Simply put, duplicate publication is a dishonest practice. As stated in the "Guidelines for Preparing Submissions to the CJHP" (available online at www.cjhp-online.ca/pages/ files/AuthorGuidelines2009E.pdf), the Journal will consider papers for publication only if they "have not been published elsewhere, including the Internet, and are not under simultaneous consideration by any other publication." Furthermore, accepted manuscripts may not be published elsewhere without 
written permission from the Journal and CSHP (the Journal's owner). The onus is on authors to withhold submission of manuscripts to the CJHP if they are under consideration elsewhere or, alternatively, to withdraw from consideration manuscripts that have been submitted to another journal if the authors wish to have the same article considered for publication by the CJHP.

The issue of plagiarism should require little discussion. Most authors understand that it is unethical to copy the work of another author and claim it as their own. But the issue of self-plagiarism, also referred to as "text reuse" or "text recycling", 8 warrants attention. Many authors and investigators conduct their work in narrow, focused areas, and in many cases the issues discussed in the background and/or discussion sections of a specific paper may be similar to issues covered in previous articles by the same author or group of authors. One must remember that, upon acceptance for publication of a manuscript by a journal, authors are usually asked to transfer copyright of the manuscript to the journal. This means that the journal's publisher, not the author, owns the material, and specific content from that article cannot be reproduced in another article for publication without the permission of the journal that published the original paper. Therefore, it is not appropriate to "self-plagiarize". There may be instances in which repeating methodology text nearly verbatim is acceptable or even recommended, for purposes of reproducibility of technically sophisticated methodology, so long as the original source is cited. However, reusing large portions of text from the introduction, methods, and discussion in more than one manuscript without substantive changes suggests an underlying intent to mislead readers, especially if the source is not cited. ${ }^{8}$ Therefore, the wording of similar background and discussion sections in different papers published by the same authors in different journals should be modified to be sufficiently dissimilar as to not constitute plagiarism. Although it could be argued that, in certain instances, there may be minimal ways in which to express an idea or concept, repeating the same passages verbatim in multiple papers should not be considered acceptable.

Numerous unfortunate examples of scientific misconduct in the form of falsification of research data have been documented in the recent literature. 'This practice should require little further discussion here: it is obviously unethical and, if discovered, may be associated with serious consequences, including withdrawal of the manuscript from the literature by the journal and discipline for academic or scientific misconduct by the individual's employer.

Finally, to maintain integrity in authorship and publication, real and potential conflicts of interest must be disclosed. Examples exist in the literature of authors failing to disclose major conflicts of interest, including the fact that they were employed by a pharmaceutical company during the conduct of a clinical trial. ${ }^{10}$ Authors submitting manuscripts to the CJHP must include in their cover letter a description of any known or suspected conflicts of interest, including any financial arrangement that any author may have with a company whose product is mentioned in the article or with a company that manufactures or distributes a competing product. If there are no conflicts of interest, a statement of this fact should be included in the cover letter. If there is any doubt, the CJHP Editor or any of the journal's Associate Editors are available to assist in determining whether a real or potential conflict exists and whether it should be disclosed. Information about real or potential conflicts of interest allows peer reviewers, editors, and readers to interpret information in light of potentially hidden and/or subconscious biases.

A common definition of integrity is doing the right thing even when no one is watching. In the case of authorship and publication, everyone is watching, or at least may be affected, because lapses in scientific integrity in the published literature may adversely affect investigators, authors, practitioners, and, ultimately, the patients for whom we provide care.

\section{References}

1. Ross JS, Hill KP, Egilman DS, Krumholz HM. Guest authorship and ghostwriting in publications related to rofecoxib: a case study of industry documents from rofecoxib litigation. JAMA 2008;299(15):1800-1812.

2. Flanagin A, Carey LA, Fontanarosa PB, Phillips SG, Pace BP, Lundberg $\mathrm{GD}$, et al. Prevalence of articles with honorary authors and ghost authors in peer-reviewed medical journals. JAMA 1998;280(3):222-224.

3. Mowatt G, Shirran L, Grimshaw JM, Rennie D, Flanagin A, Yank V, et al. Prevalence of honorary and ghost authorship in Cochrane reviews. JAMA 2002;287(21):2769-2771.

4. Flanagin A. Ethical and legal considerations: duplicate publication. In: Iverson C, Christiansen S, Flanagin A, Fontanarosa PB, Glass RM, Gregoline $\mathrm{B}$, et al. AMA manual of style: a guide for authors and editors. 10th ed. New York (NY): Oxford University Press; 2007. p. 148-149.

5. DeAngelis CD. The Roman article: read it again -in the same journal [editorial]. JAMA 2009;301(13):1382-1383.

6. Von Elm E, Poglia G, Walder B, Tramèr MR. Different patterns of duplicate publication: an analysis of articles used in systematic reviews. JAMA 2004;291(8):974-980.

7. Tramèr MR, Reynolds DJ, Moore RA, McQuay HJ. Impact of covert duplicate publication on meta-analysis: a case study. BMJ 1997; 315(7109):635-640.

8. Bird SB, Sivilotti MLA. Self-plagiarism, recycling fraud, and the intent to mislead [editorial]. J Med Toxicol 2008;4(2):69-70.

9. Eisenach JC. Data fabrication and article retraction: how not to get lost in the woods [editorial]. Anesthesiology 2009;110(5):955-956.

10. Lu-Yao G, Albertson P, Shih W, Yao S-L. Failure to report financial disclosure information [letter]. JAMA 2009;301(1):35-36.

James E Tisdale, PharmD, is Professor, School of Pharmacy \& Pharmaceutical Sciences, Purdue University, and Adjunct Professor, School of Medicine, Indiana University, Indianapolis, Indiana. He is also an Associate Editor with the CJHP.

Address correspondence to:

Dr James E Tisdale

School of Pharmacy \& Pharmaceutical Sciences

Purdue University

W7555 Myers Building, WHS

1001 West 10th Street

Indianapolis IN 46202 USA

e-mail: jtisdale@iupui.edu 